\title{
Pattern of thyroid disorders in ENT OPD of Nobel Medical College in Eastern Nepal
}

\author{
Sanjeev Kumar Thakur ${ }^{1}$, Manish Agrawal ${ }^{2}$, Nisha Ghimire ${ }^{3}$, R K Bedajit ${ }^{4}$, Pratap Roy ${ }^{5}$. \\ ${ }^{1}$ Lecturer, Department of Otolaryngology, Nobel Medical College, Biratnagar. \\ ${ }^{2}$ Lecturer, Department of Maxillofacial Surgery, Birat Medical College, Biratnagar. \\ ${ }^{3}$ Assistant Professor, Department of Physiology, Nobel Medical College, Biratnagar. \\ ${ }^{4}$ Professor and Head, Department of Otolaryngology, Nobel Medical College, Biratnagar. \\ ${ }^{5}$ Lecturer, Department of Endocrinology, Nobel Medical College, Biratnagar.
}

\begin{abstract}
Background: Thyroid dysfunction is a major health problem in eastern Nepal with a high prevalence and the pattern of thyroid disorders. Previous studies have shown the tendency of hypothyroidism to increase with the age and being more common in women.

Objective: this study was undertaken to study the various possible manifestations of thyroid disorders and their relation to age in female population in eastern Nepal.

Methods: This was a hospital based study, conducted in the Department of ENT of Nobel Medical College and teaching hospital in eastern Nepal. A total of 153 female subjects, who attended the outpatients department (OPD) for thyroid screening were enrolled in the study. Blood samples were collected and thyroid assay was done (fT3, fT4, and TSH). Data was tabulated and analysed.

Results: On analyzing the Thyroid profile of 153 subjects, 107 (69.93\%) of them were found to be of euthyroid status. Rest of them had abnormal status. Subclinical hypothyroidism status was found in 31 $(20.26 \%)$ subjects, while frank hypothyroidism was found in $9(5.88 \%)$ cases. Subclinical hyperthyroidism and frank hyperthyroidism was found in $3(1.96 \%)$ cases each. The fT3 level was of high normal level in the less than 40 years age group, while it was low normal in the above 40 years age group. On analysis, with ANOVA, there was significant difference in fT3 values among three age groups. But, no significant difference was found for fT4 level among age groups. The TSH level was shown to differ significantly among three different age groups. The normal range of TSH increased with increasing age. On analyzing the correlation of Thyroid function parameters, fT3 and fT4 values did not correlate with age, but, TSH was positively correlated with age. This signifies that TSH increases with increasing age, which is also similar to the ANOVA results.

Conclusion: the prevalence of thyroid disorder in the studied sample of eastern Nepal is found to be $30.07 \%$ and hypothyroidism was the commonest disorder in this study. There is a tendency of fT3 to decrease and TSH to increase with increasing age. However no definite pattern was found for fT4.
\end{abstract}

Key Words: Thyroid stimulating hormone, Thyroid disorders, Hypothyroidism, Euthyroid, Hyperthyroidisn, Nepal.

\section{Introduction:}

Abnormal level of Thyroid Stimulating Hormone (TSH) with normal or abnormal thyroid hormones, Free Tri-iodothyronine (FT3) and FreeTetraiodothyronine (FT4) constitutes the thyroid disorder. It is the most common endocrine disorder

Corresponding Author: Sanjeev Kumar Thakur, Lecturer, Department of Otolaryngology, Nobel Medical College, Biratnagar. affecting more than 300 million people worldwide and almost half of them are presumed to be unaware of their condition. ${ }^{1}$

Thyroid dysfunction is also a major health problem in eastern Nepal with a high prevalence and the pattern of thyroid disorders, which in turn depends on several factors like ethnicity, geographic and environmental 
Pattern of thyroid disorders in ENT OPD of Nobel Medical College... Jour of Diab and Endo Assoc of Nepal 2019; 3 (1):(26-31) factors including iodine intake status. ${ }^{2,3}$

Nepal is a mountainous land locked area, far from sea, and is an endemic zone of iodine deficiency. The iodine deficiency has been regarded as the commonest cause of thyroid disorders worldwide and in Nepal. ${ }^{4}$

Congenital factors, pregnancy, radiotherapy, viral infections, surgery, underlying diseases such as infiltrative disorders, or even autoimmunity are the other causes of thyroid disorders prevalent. ${ }^{5,6}$

Few studies revealed that the incidence of thyroid disorder increase as the age advances. Studies in developed countries have shown the tendency of hypothyroidism to increase with the age and being more common in women. ${ }^{7,8}$

Yadav and colleagues found that the prevalence of hypothyroidism was higher than hyperthyroidism in the population, and it was more common in older women. ${ }^{9}$

Hence this study was undertaken to study the various possible manifestations of thyroid disorders and their relation to age in female population in eastern Nepal.

\section{Methods:}

This was a hospital based study, conducted in the Department of ENT of Nobel Medical College and teaching hospital in eastern Nepal. A total of 153 female subjects, who attended the outpatients department (OPD) for thyroid screening were enrolled in the study. The patients with incomplete thyroid function test and reports from hemolyzed samples were not taken under consideration in this study. Also the subjects with pregnancy and multiple endocrine disorders were excluded from our study.

\section{Sample collection}

The blood sample was collected through Vacutainer tube. Samples were centrifuged immediately after clotting and the serum was stored at -200 Centigrade until assayed.

\section{Assay of the thyroid panel}

Assessment of fT3, fT4 and TSH was done by the ADVIA Centaur ${ }^{\circledR}$ CP Immunoassay System of SIEMENS company by Chemiluminescence Immunoassay (CLIA) method. All the three parameters were estimated following the standard protocol as per manufacturer's guidelines. The reference interval for fT3, fT4 and TSH were 2.3$4.2 \mathrm{pg} / \mathrm{ml}, 0.89-1.76 \mathrm{ng} / \mathrm{dL}$ and $0.35-5.5 \mathrm{microIU} /$ $\mathrm{ml}$ respectively. After the assay, data were recorded.

\section{Diagnosis and definitions}

The diagnosis of thyroid disorders was based exclusively on hormonal assay of the participants. Suspected cases of thyroid disorder after clinical examination were sent from ENT Out Patient Department (OPD) and based on their provisional diagnosis and lab report we categorized the participants as follows. No any further immunoassay of antibodies was performed. Overt Hyperthyroidism was defined as TSH of $<0.35$ microIU/ml plus high fT4 $(>1.76 \mathrm{ng} / \mathrm{ml})$ and high fT3 $(>4.2 \mathrm{pg} / \mathrm{ml})$. Overt Hypothyroidism was defined as increased TSH $(>5.5$ microIU/ $\mathrm{ml})$ plus low fT4 $(<0.89 \mathrm{ng} / \mathrm{ml})$ and fT3 $(<2.3$ $\mathrm{pg} / \mathrm{ml}$ ). Subclinical hyperthyroidism was defined as TSH $<0.35 \mathrm{microIU} / \mathrm{ml}$ and normal fT4 and fT3. Subclinical hypothyroidism was defined as increased TSH ( $>5.5 \mathrm{microIU} / \mathrm{ml})$ plus normal fT4 and fT3. Euthyroidism was defined as normal level of TSH, fT4 and fT3.

Data were analyzed using Statistical Package of Social Science (SPSS), version 16. Differences were considered significant when P-value was $<0.05$.

\section{Results:}

Table1: Diagnosis of Thyroid profile assay

\begin{tabular}{|l|l|l|}
\hline Diagnosis & Number & Percentage \\
\hline Euthyroid & 107 & $69.93 \%$ \\
\hline Subclinical hypothyroidism & 31 & $20.26 \%$ \\
\hline Hypothyroidism & 9 & $5.88 \%$ \\
\hline Hyperthyroidism & 3 & $1.96 \%$ \\
\hline Subclinical hyperthyroidism & 3 & $1.96 \%$ \\
\hline Total & 153 &
\end{tabular}


Pattern of thyroid disorders in ENT OPD of Nobel Medical College...

Jour of Diab and Endo Assoc of Nepal 2019; 3 (1):(26-31)

ISSN Print 2594-3367

ISSN Online 2631-2107

On analyzing the Thyroid profile of 153 subjects, 107 (69.93\%) of them were found to be of euthyroid status, as shown in table 1. Rest of them had abnormal status. Subclinical hypothyroidism status was found in 31 (20.26\%) subjects, while frank hypothyroidism was found in $9(5.88 \%)$ cases. Subclinical hyperthyroidism and frank hyperthyroidism was found in $3(1.96 \%)$ cases each.

Table 2. Mean and Standard deviation of thyroid function test parameters among age groups in Euthyroid status.

\begin{tabular}{|l|l|l|l|l|}
\hline $\begin{array}{l}\text { Thyroid } \\
\text { parameters }\end{array}$ & $\begin{array}{l}\text { Age Range 8-20 } \\
\text { years, } \mathrm{n}=37\end{array}$ & $\begin{array}{l}\text { Age range 21-40 } \\
\text { years, } \mathrm{n}=30\end{array}$ & $\begin{array}{l}\text { Age range 41-60 } \\
\text { years, } \mathrm{n}=40\end{array}$ & Anova(p -value) \\
\hline $\begin{array}{l}\text { Free T3 } \\
(\text { Mean } \pm \text { SD) }\end{array}$ & $3.15 \pm .40$ & $3.28 \pm .33$ & $3.07 \pm .35$ & .049 \\
\hline $\begin{array}{l}\text { Free T4 } \\
(\text { Mean } \pm \text { SD) }\end{array}$ & $1.31 \pm .183$ & $1.27 \pm .210$ & $1.32 \pm .387$ & .066 \\
\hline TSH $($ Mean \pm SD) & $2.13 \pm 1.233$ & $2.46 \pm 1.202$ & $2.97 \pm 1.402$ & .031 \\
\hline
\end{tabular}

The table shows that the fT3 level was of high normal level in the less than 40 years age group, while it was low normal in the above 40 years age group. On analysis, with ANOVA, there was significant difference in fT3 values among three age groups. But, no significant difference was found for fT4 level among age groups. The TSH level was shown to differ significantly among three different age groups. The normal range of TSH increased with increasing age.

Table 3. Correlation of fT3, fT4 and TSH values to age groups

\begin{tabular}{|l|l|l|l|l|l|l|}
\hline & fT3 & & fT4 & & TSH & \\
\hline & $\begin{array}{l}\text { Correlation } \\
\text { coefficient }\end{array}$ & P value & $\begin{array}{l}\text { Correlation } \\
\text { coefficient }\end{array}$ & P value & $\begin{array}{l}\text { Correlation } \\
\text { coefficient }\end{array}$ & P value \\
\hline Age & -.067 & .490 & .016 & .866 & $.251^{* * *}$ & .009 \\
\hline
\end{tabular}

On analyzing the correlation of Thyroid function parameters, fT3 and fT4 values did not correlate with age, but, TSH was positively correlated with age, as shown in table 3 . This signifies that TSH increases with increasing age, which is also similar to the ANOVA results in Table no 2.

\section{Discussion}

Diseases of thyroid gland are amongst the most common endocrine disorder in the world, second only to diabetes mellitus. ${ }^{10}$ Endocrine diseases are increasing globally and are also growing more rapidly in Asia. ${ }^{11}$

Iodine deficiency has been a major cause of morbidity in the past and at present, thyroid disorders other than iodine deficiency disorders in the form of thyroiditis, hypothyroidism or autoimmune thyroid dysfunctions are also on the rise. The WHO estimates that substantially greater than 190 million suffer from iodine deficiency disorders. ${ }^{12}$ Nepal is an endemic area with regard to iodine deficiency and nutritional iodine deficiency are thought to be prevalent in all Himalayan, sub-Himalayan and Terai regions of Nepal. ${ }^{4}$

A total of 153, all female were our subjects of this study. Thyroid disease is a very common endocrine disorder, and female are more prone, according to a study. ${ }^{13}$

Wang and colleagues stated that the prevalence of hypothyroidism, both subclinical and overt, among adult females from all age groups ranges from $3 \cdot 0$ to $7 \cdot 5 \%$ and it was seen more frequently in elderly 
Pattern of thyroid disorders in ENT OPD of Nobel Medical College... Jour of Diab and Endo Assoc of Nepal 2019; 3 (1):(26-31) women. ${ }^{8}$ Similar results have been found in another study done in developed country. ${ }^{14}$

In our study, on analyzing the Thyroid profile of 153 subjects, 107 (69.93\%) of them were found to be of euthyroid status. Subclinical hypothyroidism status was found in $31(20.26 \%)$ subjects, while frank hypothyroidism was found in 9 (5.88\%) cases. Subclinical hyperthyroidism and frank hyperthyroidism was found in $3(1.96 \%)$ cases each.

A survey done by Baral et al. in Eastern Nepal found that $12.9 \%$ of the population were deficient in iodine, compared with a countrywide prevalence of $18 \% .{ }^{15}$ A similar study observed nearly $30 \%$ of the population were suffering from thyroid dysfunction in eastern part of Nepal. ${ }^{2}$ The prevalence of hypothyroidism in various studies from around the world shows a considerable variation and its current prevalence ranges from as low as $1 \%$ to as high as $20 \%$ for subclinical and $1-2 \%$ for overt hypothyroidism. ${ }^{3}$

It has been reported earlier that a $20 \%$ overall prevalence of thyroid dysfunctions has been found in eastern Nepal in subject above 20 years of age. ${ }^{16}$ Few studies were in affirmation with the study which reported a higher prevalence of the subclinical hypothyroidism and overt hypothyroidism in female. ${ }^{7,17}$

Furthermore, hypothyroidism is the most common thyroid disorder in the adult population and is more common in older women. ${ }^{18}$ However, thyroid dysfunction in elderly individuals often occurs unnoticed, and methods for accurate detection may be controversial. ${ }^{19}$ Hypothy-roidism is usually autoimmune in origin, presenting as either primary atrophic hypothyroidism or Hashimoto's thyroiditis and rarely pituitary or hypothalamic disorders can result in secondary hypothyroidism. ${ }^{19}$

By contrast hyperthyroidism is much less common compared to hypothyroidism. Graves' disease is the most common cause and affects primarily young adults. Toxic multi-nodular goiters tend to affect the older age-groups. ${ }^{19}$

A study by Niafar et al found an overall $12.7 \%$ prevalence of thyroid dysfunction. Of the 73 participants with high TSH levels, 15 (20.5\%) had overt hypothyroidism, and of the 54 participants with low TSH levels, $12(22.2 \%)$ had overt hyperthyroidism. Only one participant $(1.85 \%)$ had T3 toxicosis. ${ }^{20}$

On analyzing the euthyroid cases, in our study, a tendency of high normal fT3 level in the less than 40 years age group was seen while low normal levels was seen in the above 40 years age group. On analysis, with ANOVA, there was significant difference in fT3 values among three age groups. But, no significant difference was found for fT4 level among age groups. The TSH level was shown to differ significantly among three different age groups. The normal range of TSH increased with increasing age. On analyzing the correlation of Thyroid function parameters, fT3 and fT4 values did not correlate with age, but, TSH was positively correlated with age. This signifies that TSH increases with increasing age, which is also similar to the ANOVA results.

It has been found that the age has an effect on the concentration of T3, T4 and TSH. A study has found that a gradual increase in autonomous tissue with age makes individual more susceptible to thyroid problems. Higher frequencies of thyroid problems are noted in people above $40 \mathrm{yrs}$ of age. ${ }^{21}$ The concentration of hormones decreases with age in both sexes but the drop is more in female than males. $^{22}$

One similar study reported the mean age of thyroid dysfunction is approximately 39 years of age, which showed the accumulation and manifestation of disorder symptoms in this age group. Few studies have revealed that incidence of thyroidism increases with advancing age..$^{8,23-25}$

The principal hormones of thyroid gland are Thyroxine (T4) and Triiodothyronine (T3) and 
Pattern of thyroid disorders in ENT OPD of Nobel Medical College... Jour of Diab and Endo Assoc of Nepal 2019; 3 (1): (26-31) their concentrations are $93 \%$ and $7 \%$ respectively. ${ }^{26}$ The free T4 in plasma is important in the metabolic control of human body and therefore free T4 is believed to be a direct indicator of thyroid status in an individual. Free T3 like free T4 measurement also reflects the thyroid status of individual accurately. ${ }^{27}$

There has been long standing controversy about the thyroid function test results in the elderly Serum $\mathrm{TSH}$, free T4, and free T3 concentrations change with aging. As one ages, changes occur in all body systems including the endocrine system. These changes may be due to the amount of hormones secreted or the sensitivity of target organs. In some cases, the changes in amount of hormones secreted may be secondary to changes in target organs (e.g., LH and FSH). In addition, there may also be some change in the rate of metabolism of other hormones (e.g., increased peripheral degradation of thyroid hormones). ${ }^{28}$

The 20-year follow-up Whickham survey showed that with increasing age, the incidence of positive antithyroid antibodies and hypothyroidism also increased. ${ }^{29}$

Serum T3 concentration was significantly lower in all groups of elderly subjects and decreased fT3 index measurements were detected in a study. It was concluded that old age, without complicating illness, is accompanied only by a decrease in the serum level of T3 and the FT3 index; values for other iodothyronines are unchanged. Clinicians should consider the age-related changes in T3 and fT3 values when interpreting thyroid function tests. ${ }^{30}$

Moreover, a recent longitudinal study from Western Australia (Busselton survey), for the first time, showed that serum TSH increases with no significant change in free $\mathrm{T} 4$ concentrations with aging. ${ }^{31}$

\section{Conclusions}

To conclude, the prevalence of thyroid disorder in the studied sample of eastern Nepal is found to be $30.07 \%$ and hypothyroidism was the commonest disorder in this study. There is a tendency of fT3 to decrease and TSH to increase with increasing age. However no definite pattern was found for fT4.

Limitations: The present study was based on routine thyroid function test i.e. serum free T3, free T4 and TSH measurement only. Total T4, Total T3, thyroglobulin, anti thyroperoxidase (antiTPO), anti-thyroglobulin (anti Tg), TSH receptor antibodies and Thyroid stimulating immunoglobulin (TSI) were not done.

\section{Recommendation}

A large scale study in the community is required to validate the findings of the pattern of thyroid disorder as found in this study. The etiological factors of thyroid dysfunction in this region of the country should be explored. A regular thyroid screening program could be helpful in identifying the thyroid endocrinological abnormality prevalent in the community.

\section{REFERENCES}

1.PAPSmyth. Epidemiology of Thyroid Dysfunction - Hypothyroidism and Hyperthyroidism. Darmstadt, Germany. 2009.

2. Baral N, Lamsal M, Koner BC, Koirala S. Thyroid dysfunction in Eastern Nepal. South East Asian J Trop Med Public Health. 2002; 33: 638-641.

3. Aminorroaya A, Janghorbani $\mathrm{M}$, Amini $\mathrm{M}$, Hovsepian S, Tabatabaei A, Fallah Z. The prevalence of thyroid dysfunction in an iodinesufficient area in Iran. Arch Iran Med. 2009: 12: 262-270.

4. Regmi A, Shah B, Rai BR, Pandeya A. Serum lipid profile in patients with thyroid disorders in central Nepal. Nepal Medical College Journal. 2010: 12: 253-256.

5. Brownlie BE, Wells JE. The epidemiology of thyrotoxicosis in New Zealand: incidence and geographical distribution in north Canterbury, 1983-1985. Clin Endocrinol 1990; 33: 249259.

6. Vanderpump MP, Tunbridge WM. Epidemiology and prevention of clinical and subclinical hypothyroidism. Thyroid. 2002; 12: 839-847. 
7. Tunbridge WM, Evered DC, Hall R, Appleton $\mathrm{D}$, Brewis M, Clark F, et al. The spectrum of thyroid disease in a community: the Whickham survey. Clin Endocrinol. 1977; 7: 481-493.

8. Wang C, Crapo LM. The epidemiology of thyroid disease and implications for screening. Endocrinol Metab Clin North Am. 1997; 26: 189-218.

9. Yadav RK, Magar NT, Poudel B, Yadav NK, Yadav B. A prevalence of thyroid disorder in Western part of Nepal. J Clin Diagn Res. 2013; 7: 193-196.

10. Heuck CC, Kalner A, Kanagasabapathy AS, Riesen W. Diagnosis and monitoring of the disease of the thyroid. World Health Organization. 2000;8-9 11. Ganie MA, Zargar AH. Scenario of endocrinology in South Asia. Indian J Endocrinol Metab. 2007;11:1-2.

12. International Council for Control of Iodine Deficiency Disorders., UNICEF. World Health Organization. Assessment of iodine deficiency disorders and monitoring their elimination: a guide for programme managers. 2nd ed. Geneva: World Health Organization; 2001.

13. Canaris GJ, Manowits NR, Mayor G, Ridgway EC. The Colorado thyroid disease prevalence study. Archives of Internal Medicine. 2000; 160: 526-534.

14. Shaw CK, Thapalia A, Nanda S, Shaw P. Thyroid dysfunction in Down syndrome. Kathmandu Univ Med J. 2006; 4: 182-186.

15. Baral N, Ramprasad C, Lamsal M, Koner BC, Koirala S. Assay of iodine deficiency status in three ecological regions of Nepal by a microdigestion method. Southeast Asian J Trop Med Public Health. 1999; 30: 527-531.

16. Shrestha S, Das BKL, Baral N, et al. Association of metabolic syndrome and its component with thyroid dysfunction in females. Int J Diab Dev Ctries 2007; 27: 24-26.

17. Surks MI, Chopra IJ, Mariash CN et al. American thy-roid association guidelines for use of laboratory tests in thyroid disorders. J A M A 1990; 263: 1529-1532.

$18 \mathrm{Wu}$ Patricia. Diabetes and thyroid disease. Clinical Diabetes 2008; 18: 111-118.

19. Dos Remedios LV, Weber PM, Feldman R et al. Detecting unsuspected thyroid dysfunction by the free thyroxine index. Arch Intern Med 1980; 140: 1045-1049.
20. Niafar M, Aliasgharzadeh A, Bahrami A, et al. Preva-lence of thyroid dysfunction in the elderly women of Iran. Endocrine Abstracts 2009; 20: 137.

21. ICCIDD- international Council for Control of Iodine Deficiency Disorder. Statement on iodine induced thyrotoxicosis; 1997.

22. Razzak MA. Effect of Age and Sex on Thyroid Function Tests Established of norms for the Egyptian Population in Development in Radioimmunoassay and Related Procedures. International Atomic Energy Agency, 1992. P.353-8.

23. Eggertsen R, Petersen K, Lundberg PA, et al. Screening for thyroid disease in a primary care unit with a thyroid stimulating hormone assay with a low detection limit. Brit Med J 1988; 297: 1586- 1592.

24. Falkenberg M, Kagedal B, Norr A. Screening of an elderly female population for hypo- and hyperthyroid-ism by use of a thyroid hormone panel. Acta Med Scand 1983; 214: 361-365

25. Arem R, Patsch W. Lipoprotein and apolipoprotein levels in subclinical hypothyroidism: effect of levothy-roxine therapy. Arch Intern Med 1990; 150: 20972100.

26. Ganong. FW. Review of Medical Physiology, California: Appleton and Lange; 1995. p.314.

27. Guyton WC, Hall 1E. A Textbook of Medical Physiology. Philadelphia: W B Saunders \& Co; 1996. p. 945-55.

28. S. Mariotti, C. Franceschi, A. Cossarizza, and A. Pinchera.The aging thyroid. Endocrine Reviews. 1995;16(6): 686-715.

29. K. A. Woeber. Aging and the thyroid.The Western Journal of Medicine. 1985;143(5): 668-669.

30. Caplan RH, Wickus G, Glasser JE, Davis K, Wahner HW. Serum concentrations of the iodothyronines in elderly subjects: decreased triiodothyronine (T3) and free T3 index. J Am Geriatr Soc. 1981;29(1):19-24.

31. A. P. Bremner, P. Feddema, P. J. Leedman et al. Age-related changes in thyroid function: a longitudinal study of a community-based cohort. Journal of Clinical Endocrinology \& Metabolism. 2012; 97:1554-1562. 